\title{
BMJ Open The accuracy of postoperative, non- invasive Air-Test to diagnose atelectasis in healthy patients after surgery: a prospective, diagnostic pilot study
}

\author{
Carlos Ferrando, ${ }^{1}$ Carolina Romero, ${ }^{2}$ Gerardo Tusman, ${ }^{3}$ \\ Fernando Suarez-Sipmann, ${ }^{4,5}$ Jaume Canet, ${ }^{6}$ Rosa Dosdá, ${ }^{7}$ Paola Valls, ${ }^{1}$ \\ Abigail Villena, ${ }^{1}$ Ferran Serralta, ${ }^{1}$ Ana Jurado, ${ }^{1}$ Juan Carrizo, ${ }^{1}$ Jose Navarro, ${ }^{1}$ \\ Cristina Parrilla, ${ }^{7}$ Jose E Romero, ${ }^{8}$ Natividad Pozo, ${ }^{9}$ Marina Soro, ${ }^{1}$ Jesús Villar, ${ }^{5,10}$ \\ Francisco Javier Belda ${ }^{1}$
}

To cite: Ferrando C, Romero C, Tusman G, et al. The accuracy of postoperative, noninvasive Air-Test to diagnose atelectasis in healthy patients after surgery: a prospective, diagnostic pilot study. BMJ Open 2017;7:e015560. doi:10.1136/ bmjopen-2016-015560

- Prepublication history and additional material for this paper are available online. To view these files please visit the journal online (http://dx.doi. org/10.1136/bmjopen-2016015560).

Received 13 December 2016 Accepted 10 March 2017

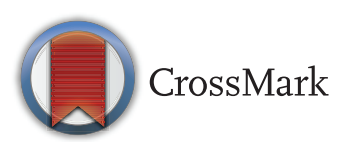

For numbered affiliations see end of article.

Correspondence to Dr Carlos Ferrando; cafeoranestesia@gmail.com

\section{ABSTRACT}

Objective To assess the diagnostic accuracy of peripheral capillary oxygen saturation $\left(\mathrm{SpO}_{2}\right)$ while breathing room air for $5 \mathrm{~min}$ (the 'Air-Test') in detecting postoperative atelectasis.

Design Prospective cohort study. Diagnostic accuracy was assessed by measuring the agreement between the index test and the reference standard CT scan images. Setting Postanaesthetic care unit in a tertiary hospital in Spain.

Participants Three hundred and fifty patients from 12 January to 7 February 2015; 170 patients scheduled for surgery under general anaesthesia who were admitted into the postsurgical unit were included.

Intervention The Air-Test was performed in conscious extubated patients after a 30 min stabilisation period during which they received supplemental oxygen therapy via a venturi mask. The Air-Test was defined as positive when $\mathrm{SpO}_{2}$ was $\leq 96 \%$ and negative when $\mathrm{SpO}_{2}$ was $\geq 97 \%$. Arterial blood gases were measured in all patients at the end of the Air-Test. In the subsequent $25 \mathrm{~min}$, the presence of atelectasis was evaluated by performing a CT scan in 59 randomly selected patients.

Main outcome measures The primary study outcome was assessment of the accuracy of the Air-Test for detecting postoperative atelectasis compared with the reference standard. The secondary outcome was the incidence of positive Air-Test results.

Results The Air-Test diagnosed postoperative atelectasis with an area under the receiver operating characteristic curve of $0.90(95 \% \mathrm{Cl} 0.82$ to 0.98$)$ with a sensitivity of $82.6 \%$ and a specificity of $87.8 \%$. The presence of atelectasis was confirmed by CT scans in all patients $(30 / 30)$ with positive and in 5 patients $(17 \%)$ with negative Air-Test results. Based on the Air-Test, postoperative atelectasis was present in $36 \%$ of the patients (62 out of 170).

Conclusion The Air-Test may represent an accurate, simple, inexpensive and non-invasive method for diagnosing postoperative atelectasis.

Trial Registration NCT02650037.

\section{Strengths and limitations of this study}

- This study used a simple and fast room air breathing trial (the 'Air-Test') in the early postoperative period to diagnose atelectasis.

- Diagnostic accuracy was assessed by measuring agreement between the index test and the reference standard CT scan images.

- This study was a pilot study, and a large external validation study is now needed.

- The Air-Test had several limitations related to the pulse oximeter and to the test itself, which could limit its clinical application in some cases.

\section{INTRODUCTION}

An estimated 234 million major surgical procedures are undertaken each year worldwide. ${ }^{1}$ Atelectasis may develop in nearly $90 \%$ of patients put under general anaesthesia and can persist during the immediate postoperative period and up to several days after surgery. ${ }^{2-5}$ Persistence of atelectasis after surgery is potentially associated with postoperative pulmonary complications such pneumonia, acute lung injury and extubation failure requiring reintubation. ${ }^{3-7}$ Hypoxaemia, a direct consequence of atelectasis, ${ }^{8}$ may also promote systemic complications such as acute myocardial ischaemia or impaired wound healing, among others. $^{9}$

Oxygen therapy is usually given in the postoperative period to alleviate hypoxaemia, ${ }^{10}$ which develops in most patients after general anaesthesia. As a result, the majority of atelectasis cases in the postoperative period cannot be diagnosed at the bedside, thus precluding the application of any corrective measures and potentially 
increasing the risk of atelectasis-related postoperative complications. However, using a low (0.21) fractional inspired oxygen $\left(\mathrm{FiO}_{2}\right)$ may improve lung function categorisation as measured by peripheral capillary oxygen saturation (pulse oximetry haemoglobin saturation; $\mathrm{SpO}_{2}$ ) values, because it forces $\mathrm{SpO}_{2}$ to operate in the steep section of the oxygen-haemoglobin dissociation curve and can therefore be used to estimate the alveolar shunt using the $\mathrm{SpO}_{2}-\mathrm{FiO}_{2}$ diagram described by Jones and Jones. ${ }^{11}$ This could help to unmask underlying oxygenation deficits caused by this shunt and thus the presence of atelectasis when $\mathrm{SpO}_{2}$ is low, although this does assume that there is a linear relationship between the alveolar shunt and atelectasis. Consequently, a combination of oxygen therapy with transitory decreases in $\mathrm{FiO}_{2}$ to 0.21 over a 5 min period is enough to achieve a steady state in the expired fractional oxygen concentration $\left(\mathrm{FEO}_{2}\right)^{12} 13$ and thus may allow estimation of the alveolar shunt in addition to revealing the presence of atelectasis in the immediate postoperative period.

We hypothesised that changes in arterial oxygen saturation induced by a short $\mathrm{FiO}_{2}$ manoeuvre to reduce it to 0.21 can be used to detect the shunt related to postoperative atelectasis. Thus, the aim of this study was to determine whether $\mathrm{SpO}_{2}$ recorded by pulse oximetry after breathing room air for 5 min (the 'Air-Test') can reveal the presence of atelectasis and to establish the relationship between $\mathrm{SpO}_{2}$ and the presence of atelectasis as assessed by a CT scan.

\section{METHODS}

\section{Study design}

We performed a prospective, cohort study in the postsurgical recovery unit at the University Clinical Hospital (Hospital Clínico Universitario) in Valencia (Spain), from 12 January to 7 February 2015. The study was approved by the Local Ethics Committee for Clinical Research (Chairperson: Dr Antonio Peláez), is in accordance with the Declaration of Helsinki on human experimentation and was registered on 28 December 2015 at http://www. clinicaltrials.gov with identification no. NCT02650037. Written informed consent was obtained from all the patients involved in the study. The complete and original protocol is described in this section.

\section{Eligibility criteria}

The study included consecutively recruited patients with an American Society of Anesthesiologists physical status of I-III who were scheduled for elective surgery with general anaesthesia and admitted to the postsurgical unit. Exclusion criteria were: (1) age $<18$ years, (2) pregnancy, (3) previous lung resection, (4) cardiac and lung resection surgery or (5) preoperative $\mathrm{SpO}_{2} \leq 97 \%$ on room air. Postoperatively, patients who had given their consent were excluded if they met any of the following criteria: (1) patients not extubated in the operating room, (2) patients requiring any kind of ventilatory support, (3) postoperative haemoglobin $<10 \mathrm{~g} / \mathrm{dL}$, (4) need for continuous vasopressor or inotropic support, (5) agitation/sedation Richmond scale $>1$ or $<-1$ and (6) pain $>4$ (evaluated with the visual analogue scale) after

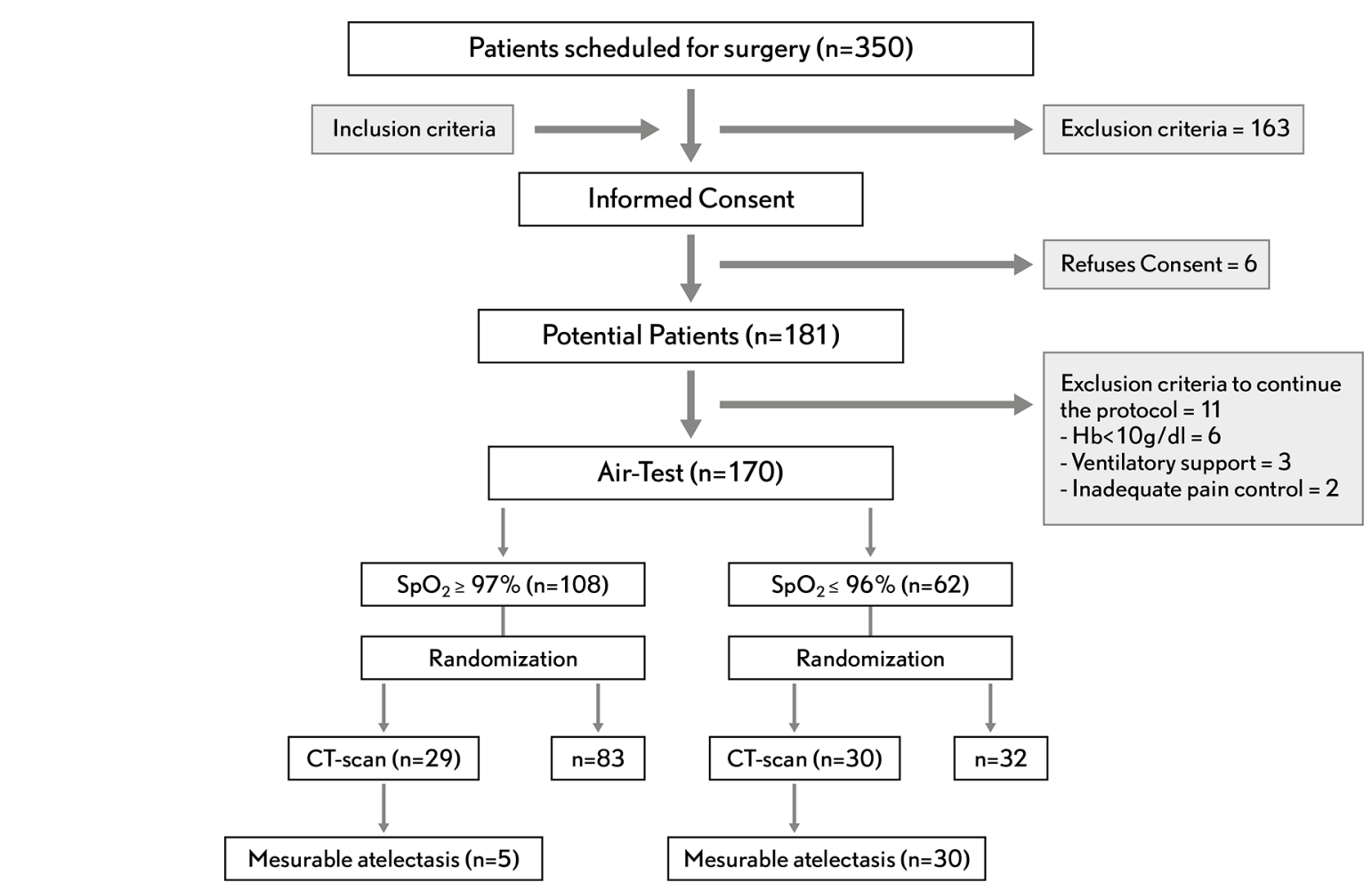

Figure 1 Standards for Reporting of Diagnostic Accuracy Studies flow diagram. 
the first $30 \mathrm{~min}$ in the postanaesthesia care unit (PACU; figure 1).

\section{Monitoring}

Intraoperative anaesthesia management followed standard clinical routines and the study started on arrival at the postsurgical unit. A multiparameter IntelliVue MX450 (Philips Healthcare, Böblingen, Germany) monitor was used for all patients to monitor the patient's heart activity (via ECG), systemic arterial pressure (non-invasively) and $\mathrm{SpO}_{2}$. The MX450 monitor pulse oximeter finger probe uses Fourier artefact-suppression technology (FAST) to measure $\mathrm{SpO}_{2}$; its characteristics are described in online supplementary 1 of this article's supporting digital content.

\section{Index test for postoperative atelectasis}

Patients received supplemental oxygen through a venturi mask with a jet and flow adjusted to a theoretical $\mathrm{FiO}_{2}$ of 0.5 for the first $30 \mathrm{~min}$. The Air-Test was then performed by removing the oxygen mask and leaving the patients breathing room air for at least $5 \mathrm{~min}$ while continuously monitoring $\mathrm{SpO}_{2}$ with a pulse oximeter finger probe. The Air-Test result was considered positive when the recorded $\mathrm{SpO}_{2}$ was $\leq 96 \%$ and negative when $\mathrm{SpO}_{2}$ was $\geq 97 \%$. We selected this cut-off value to diagnose atelectasis based on the $\mathrm{SpO}_{2}-\mathrm{FiO}_{2}$ diagram ${ }^{10}$ described by Jones showing that $\mathrm{SpO}_{2} \leq 96 \%$ corresponds to a shunt effect of more than $10 \%$ and defines alveolar collapse. Recently, Tusman et $a l^{14}$ used a similar approach by using a $\mathrm{FiO}_{2}$ of 0.21 to define an open-lung condition in anaesthetised patients while ventilated.

We used a 5 min time interval based on the results we obtained in our pilot study performed with 10 healthy non-smoker volunteers at the Private Community Hospital (Hospital Privado de Comunidad in its original Spanish) in Mar del Plata (Argentina) to establish the mean time from removal of a venturi mask providing oxygen supplementation to detection of a $\mathrm{FEO}_{2}$ stabilisation signal-in this case, $56( \pm 7)$ s. Interventions and results are described in online supplementary 1 of our additional digital content. Furthermore, the selected time was also based on results from spontaneously breathing patients published by Howe $e t a l^{12}$ and in mechanically ventilated patients described by Fildissis et al. ${ }^{13}$ Both studies showed that the partial-pressure of oxygen in arterial blood $\left(\mathrm{PaO}_{2}\right)$ measured $5 \mathrm{~min}$ after discontinuation of supplementary oxygen represents a steady-state condition in lung-healthy patients.

The Air-Test was performed 30 min after PACU admission for safety reasons. This arbitrary time restraint was set to provide sufficient time for staff to carry out all the necessary tests and to check that patients met all the discharge criteria, thus ensuring their safe release from the PACU after having received general anaesthesia. The reference standard test for postoperative atelectasis (a CT scan) was performed in a random selection of these patients as soon as possible after completing the Air-Test (in order to minimise bias). In addition, we evaluated the prevalence of positive Air-Test results. Once the Air-Test was completed, a blood sample was drawn from each patient while breathing room air in order to perform an arterial blood gas analysis (Radiometer ABL 520 blood gas analyser, Radiometer, Copenhagen, Denmark). The oxygen mask was placed back whenever their $\mathrm{SpO}_{2}$ fell to $92 \%$ for more than 1 min during the Air-Test and until the end of the protocol after the Air-Test was completed.

\section{Randomisation of patients for the reference standard test (CT scan)}

Approximately $25 \mathrm{~min}$ later, patients were randomly selected to undergo a CT scan evaluation-the gold standard technique used for diagnosing atelectasis. We used adaptive randomisation that allowed us to minimise the CT scan exposure in patients not expected to have atelectasis while maintaining a sufficient number of patients on each arm to be able to conduct adequate statistical comparisons. ${ }^{15}$

\section{Postoperative atelectasis (CT scan) reference standard test}

For the purpose of this study and based on previous data, ${ }^{14}$ the presence of an atelectatic area of less than $2 \%$ in the CT scan was considered negligible (negative), because it does not cause a clinically relevant alveolar shunt. ${ }^{16}{ }^{17}$ CT scans were acquired with 16 detectors per row and 32 slices using an Aquilion LB scanner (Toshiba). Scans (120 kV, 100-140 mA and $0.5 \mathrm{~s}$ rotation time) were obtained during an expiratory hold after a normal inspiration. The images were reconstructed in $5 \mathrm{~mm}$ thickness slices with $5 \mathrm{~mm}$ intervals and with a depth of 12 bits per pixel. Each right and left surface of normally aerated tissue and atelectasis were semi-automatically delineated. To this aim a customised MATLAB script was used to automatically select the normally aerated lung surface with a window setting of -1000 to +100 Hounsfield units (HU). Segmentation was manually corrected by an expert to remove the heart, the major vessels, the bronchus and artefacts and to delineate the atelectatic tissue. Finally, an automatic thresholding was applied to the atelectasis regions (HU from -100 to +100 ). After this correction, normally aerated lung and atelectasis tissue separation was automatically corrected. . CT densities were quantitatively analysed using previously validated methods. ${ }^{18} 19$ The atelectatic area was expressed in square centimetre as the mean and SD and as a percentage of the total lung area. Volumes for the different segmented regions of interest (ROIs) were calculated using equation 1:

$$
V O L_{R O I}=\sum_{V} x * y * z * 0.001
$$

Where $V$ is the set of voxels inside the ROI and $x, y$ and $z$ are the voxel sizes in the three dimensions, in millimetres. Volumes are given in millilitres.

The lung tissue masses for the different ROIs were calculated as previously described. ${ }^{20}$ See equation 2 : 


$$
M A S S_{R O I}=\sum_{i \in V} \frac{\left(H U_{i}+1000\right) * V O L_{\text {voxel }}}{1000}
$$

Where $V$ represents the set of voxels inside the ROI under study, $i$ represents the voxel index from $V, H U_{i}$ represents the $C T$ value for voxel $i$, and $V O L_{\text {voxel }}$ represents the voxel volume for the image being processed, in millilitres. The atelectatic mass was expressed in grams as the mean \pm SD and as a percentage of the total lung mass. The thoracic level for CT scan analysis was not predefined but was performed at the region presenting the largest amount of atelectasis, independently in each lung. All CT images were analysed by the same radiologist and computer engineer who were blinded to the purpose of the study.

\section{Index test (Air-Test) diagnostic test}

A $2 \times 2$ table was used to assess the sensitivity $=(\mathrm{TP} /$ $(\mathrm{TP}+\mathrm{FN})) \times 100, \quad$ specificity $=(\mathrm{TN} /(\mathrm{FP}+\mathrm{TN})) \times 100 \quad$ and diagnostic accuracy $=((\mathrm{TP}+\mathrm{TN}) /(\mathrm{TP}+\mathrm{TN}+\mathrm{FP}+\mathrm{FN})) \times 100$ of the Air-Test, where TP is true positive, $\mathrm{TN}$ is true negative, FP is false positive and $\mathrm{FN}$ is false negative.

\section{Statistical analysis}

The total sample size was not calculated because this was a cohort study. Similarly, the sample size for the randomised CT scan group was not calculated because this was preliminary pilot study. Thus, we arbitrarily decided that the minimum sample size should be at least 50 patients (25 patients each with positive or negative Air-Test results). Data were analysed using the statistical software R, V.3.1.1. ${ }^{21}$ All the analyses performed were prespecified, and statistical description of the baseline demographics were obtained from the Rmisc and PropCIs libraries. We compared postoperative variables either using the Student's t-test or Mann-Whitney U test for continuous variables, depending on their characteristics: the Shapiro-Wilk test was used to assess normality, the Friedman test for ordinal variables and the binomial test for proportional variables. Data are expressed as the mean $( \pm \mathrm{SD})$ or median (IQR).

We used a simple linear regression model with the $\mathrm{SpO}_{2}$ and total atelectasis area variables using the following formula: area of atelectasis $\sim \mathrm{SpO}_{2}+\varepsilon$, where $\varepsilon$ is the error and a regression line was built on the resulting scatterplot using the $\operatorname{lm}($ ) function. The diagnostic accuracy and sensitivity analysis were conducted in $\mathrm{R}$ with the $p R O C$ library. The CIs of the thresholds or the sensitivity and specificity values were computed with bootstrap resampling and averaging methods, as described by Fawcett, ${ }^{22}$ which have been shown to generate unbiased optimism-adjusted estimates of the CI statistics. The patients were resampled for all bootstrap CIs, and the modified curve was built before the statistics of interest were computed. As in the bootstrap comparison test, the resampling was stratified. ${ }^{23}$ For all comparisons, a two-sided value of $\mathrm{p}<0.05$ was considered significant.

\section{RESULTS}

A total of 181 out of 350 eligible patients scheduled for surgery were enrolled; 170 of these underwent the Air-Test in the postoperative unit; 30 randomly assigned patients from the 62 positive Air-Test results and 29 from the 108 negative Air-Test results were also assessed with CT imaging (figure 1).

\section{Baseline demographic and clinical characteristics of all the patients}

The demographic, surgical, intraoperative ventilatory management data and clinical variables after the completion of the Air-Test are shown in table 1. Patients with positive Air-Test results were older, predominantly male, had a higher Assess Respiratory Risk in Surgical Patients in Catalonia ${ }^{24}$ score and weighted more compared with those with negative test results. There were no significant differences regarding intraoperative management, type and surgery duration between either group. Oxygenation (ie, $\mathrm{PaO}_{2}$ ) was $25 \%$ lower in patients with a positive test result $(\mathrm{p}<0.001)$. In addition, $\mathrm{SpO}_{2}$ fell in the steep section of the oxygen-haemoglobin dissociation curve for patients with positive test result but not for patients with a negative test result. All the patients were haemodynamically stable and normothermic.

\section{Baseline demographic and clinical characteristics of patients in the reference standard (CT scan) group}

As shown in table 2, the differences found between patients with positive and negative Air-Test results (table 1) were maintained in patients who also underwent a CT scan.

\section{Diagnostic accuracy}

Of the 59 patients evaluated with a CT scan, all those with a positive Air-Test and 5 of those with a negative Air-Test result $(17 \%)$ had a measurable atelectasis (area $>2 \%$ of the whole lung) on their CT scan. When mass analysis was used to diagnose atelectasis, 27 patients with a positive Air-Test result and only 3 patients with a negative Air-Test result had measurable atelectasis (mass $>2 \%$ of the whole lung). None of the patients with a negative Air-Test result and atelectasis on their CT scan had $\mathrm{SpO}_{2}>98 \%$ and an atelectatic area or mass $>4 \%$. Receiver operating characteristic (ROC) analysis showed that a positive Air-Test $\left(\mathrm{SpO}_{2} \leq 96 \%\right)$ result was adequate to diagnose postoperative atelectasis (table 3 ).

\section{Sensitivity analysis}

Since the Air-Test could be affected by several factors such as dyshaemoglobinaemia, low-perfusion status, motion artefact and hypothermia, we performed two additional analyses to confirm our results. First, the $\mathrm{PaO}_{2}$ threshold value confirming the diagnosis of atelectasis was $78 \mathrm{~mm} \mathrm{Hg}$, with a sensitivity of $82.6 \%$, a specificity of $78.7 \%$ and an area under the ROC curve of 0.86 (95\% CI $76.6 \%$ to $96.1 \%$ ). Second, to check the suitability of $\mathrm{SpO}_{2}$ for diagnosing atelectasis, we performed an ROC test for correlated data between $\mathrm{SpO}_{2}$ ROC and $\mathrm{PaO}_{2}$ ROC. 
Table 1 Patient study variables in the positive and negative Air-Test results groups

Positive Air-Test result $(n=62) \quad$ Negative Air-Test result $(n=108) \quad p$ Value

\begin{tabular}{|c|c|c|c|}
\hline \multicolumn{4}{|l|}{ Demographic data } \\
\hline Age, years & $65(11)$ & $56(17)$ & $<0.001$ \\
\hline Women, n (\%) & $33(6)$ & $56(9)$ & 0.01 \\
\hline Height, cm & $164(9)$ & $166(9)$ & 0.06 \\
\hline Body weight, kg & $84(21)$ & $73(15)$ & $<0.001$ \\
\hline ARISCAT score & $26(14)$ & $16(15)$ & 0.01 \\
\hline Preoperative $\mathrm{SpO}_{2}, \%$ & $98(1)$ & $98(2)$ & 0.12 \\
\hline Lower abdominal surgery & $24(38)$ & $34(31)$ & 0.20 \\
\hline Upper abdominal surgery & $9(14)$ & $13(12)$ & 0.11 \\
\hline Peripheral surgery & $29(46)$ & $60(55)$ & 0.06 \\
\hline Duration of surgery, min & $137(62)$ & $119(63)$ & 0.27 \\
\hline \multicolumn{4}{|c|}{ Intraoperative ventilatory management } \\
\hline Tidal volume, $\mathrm{mL}$ & $470(52)$ & $460(88)$ & 0.33 \\
\hline Respiratory rate, breaths/min & $12(1)$ & $12(2)$ & 1.00 \\
\hline PEEP, $\mathrm{cmH}_{2} \mathrm{O}$ & $6(1)$ & $6(2)$ & 1.00 \\
\hline $\mathrm{FiO}_{2}$ & $0.6(0.2)$ & $0.7(0.3)$ & 0.88 \\
\hline \multicolumn{4}{|c|}{$\mathrm{SpO}_{2}$ and arterial blood gases in PACU at the end of the Air-Test } \\
\hline Postoperative $\mathrm{SpO}_{2}, \%$ & $91(3)$ & $99(1)$ & 0.01 \\
\hline $\mathrm{PaO}_{2}, \mathrm{~mm} \mathrm{Hg}$ & $66(10)$ & $87(12)$ & 0.01 \\
\hline $\mathrm{PaCO}_{2}, \mathrm{~mm} \mathrm{Hg}$ & $41(6)$ & $42(6)$ & 0.29 \\
\hline $\mathrm{pH}$ & $7.37(0.04)$ & $7.38(0.03)$ & 0.06 \\
\hline MAP, $\mathrm{mm} \mathrm{Hg}$ & $79(12)$ & $85(15)$ & 0.07 \\
\hline Lactate, $\mathrm{mmol} / \mathrm{L}$ & $1.1(0.4)$ & $1.0(0.7)$ & 0.32 \\
\hline $\mathrm{Hb}, \mathrm{g} / \mathrm{dL}$ & $12.6(1.7)$ & $12.9(1.1)$ & 0.09 \\
\hline Temperature, ${ }^{\circ} \mathrm{C}$ & $36.4(1.9)$ & $36.1(2.1)$ & 0.41 \\
\hline VAS & 1 (1) & $1(1)$ & 1.00 \\
\hline
\end{tabular}

Data are described as the mean $( \pm$ SD) or number/total number (\%). The ARISCAT score was used to predict postoperative pulmonary complications. ${ }^{22}$

ARISCAT, Assess Respiratory Risk in Surgical Patients in Catalonia; $\mathrm{FiO}_{2}$, inspiratory oxygen fraction; $\mathrm{Hb}$, haemoglobin; MAP, mean arterial pressure; $\mathrm{PaCO}_{2}$, carbon dioxide partial pressure; PACU, postanaesthesia care unit; $\mathrm{PaO}_{2}$, arterial oxygen partial pressure; PEEP, positive end-expiratory pressure; $\mathrm{pH}$, acid-base status; $\mathrm{SpO}_{2}$, pulse oximetry haemoglobin saturation; VAS, visual analogue scale.

The ROC test showed no differences between either test $(\mathrm{p}=0.10)$.

\section{Secondary outcome}

We found a prevalence of positive Air-Test results of $36 \%$ in our population (62 of the 170 patients).

\section{Adverse events}

No adverse events were reported during the study period.

\section{DISCUSSION}

This diagnostic pilot study showed that performing a postoperative Air-Test $30 \mathrm{~min}$ after surgery could accurately diagnose atelectasis and identified a high prevalence postoperative atelectasis. This simple, non-invasive and inexpensive bedside test can be used in healthy patients with a preoperative $\mathrm{SpO}_{2}$ between $97 \%$ and $100 \%$ while breathing room air and helped to unmask underlying oxygenation deficits and the presence of atelectasis when $\mathrm{SpO}_{2}$ is $\leq 96 \%$. As previous studies have described, the alveolar shunt induced by atelectasis is the main cause of oxygenation impairment during the postoperative period. ${ }^{15}$ In fact, Rothen et $a l^{25}$ showed that $75 \%$ of $\mathrm{PaO}_{2}$ impairment is related to atelectasis and airway closure in patients with healthy lungs. Based on this statement, our results are in line with those of Witting and Lueck, ${ }^{26}$ who found that an $\mathrm{SpO}_{2}$ of $\leq 96 \%$ in patients breathing room air was synonymous with a diagnosis of hypoxaemia (defined as $\mathrm{PaO}_{2}<70 \mathrm{~mm} \mathrm{Hg}$ in their study) with a sensitivity of $100 \%$, a specificity of $54 \%$ and an area under the ROC curve of 0.91 (95\% CI 0.78 to 0.94 ).

We found a rate of $17 \%$ false-negative Air-Test results in patients who presented an atelectasis area higher than $2 \%$ in their CT images, which reduced to $10 \%$ when mass was used to diagnose atelectasis. There are several potential reasons for this decreased sensitivity. First, the test duration: 
Table 2 Study variables of patients in the positive and negative Air-Test results groups also assessed with a reference standard CT scan

\begin{tabular}{|c|c|c|c|}
\hline & Positive Air-Test result $(n=30)$ & Negative Air-Test result $(n=29)$ & p Value \\
\hline \multicolumn{4}{|l|}{ Demographic data } \\
\hline Age, years & $62(13)$ & $53(15)$ & 0.045 \\
\hline Women, $\mathrm{n}(\%)$ & $12(40)$ & $11(37)$ & 0.57 \\
\hline Height, cm & $165(10)$ & $163(12)$ & 0.32 \\
\hline Body weight, $\mathrm{kg}$ & $88(29)$ & $75(17)$ & $<0.001$ \\
\hline ARISCAT score & $28(14)$ & $14(15)$ & $<0.001$ \\
\hline Preoperative $\mathrm{SpO}_{2}, \%$ & $98(2)$ & $98(2)$ & 0.28 \\
\hline Lower abdominal surgery & $39(10)$ & $29(5)$ & 0.20 \\
\hline Upper abdominal surgery & $6(3)$ & $4(3)$ & 0.11 \\
\hline Peripheral surgery, \% & $55(11)$ & $67(7)$ & 0.06 \\
\hline Duration of surgery, min & $137(62)$ & $119(63)$ & 0.27 \\
\hline \multicolumn{4}{|c|}{ Intraoperative ventilatory management } \\
\hline Tidal volume, $\mathrm{mL}$ & $472(50)$ & $466(92)$ & 0.56 \\
\hline Respiratory rate, breaths/min & $12(1)$ & $12(2)$ & 1.00 \\
\hline PEEP, $\mathrm{cmH}_{2} \mathrm{O}$ & $6(1)$ & $6(2)$ & 1.00 \\
\hline $\mathrm{FiO}_{2}$ & $0.7(0.2)$ & $0.7(0.3)$ & 0.90 \\
\hline \multicolumn{4}{|c|}{$\mathrm{SpO}_{2}$ and arterial blood gases at PACU at the end of the Air-Test } \\
\hline Postoperative $\mathrm{SpO}_{2}, \%$ & $92(3)$ & $99(1)$ & 0.01 \\
\hline $\mathrm{PaO}_{2}, \mathrm{~mm} \mathrm{Hg}$ & $78(21)$ & $90(10)$ & $<0.001$ \\
\hline $\mathrm{PaCO}_{2}, \mathrm{~mm} \mathrm{Hg}$ & $40(6)$ & $42(6)$ & 0.34 \\
\hline $\mathrm{pH}$ & $7.37(0.04)$ & $7.38(0.03)$ & 0.09 \\
\hline MAP, $\mathrm{mm} \mathrm{Hg}$ & $81(12)$ & $76(15)$ & 0.72 \\
\hline Lactate, $\mathrm{mmol} / \mathrm{L}$ & $1.1(0.4)$ & $1.0(0.6)$ & 0.52 \\
\hline $\mathrm{Hb}, \mathrm{g} / \mathrm{dL}$ & $12.5(1.2)$ & $12.3(1.6)$ & 0.41 \\
\hline Temperature, ${ }^{\circ} \mathrm{C}$ & $36.2(1.9)$ & $36.2(2.3)$ & 0.68 \\
\hline VAS & $1(1)$ & $1(1)$ & 1.00 \\
\hline
\end{tabular}

Data are described as mean (SD) or number/total number (\%). The ARISCAT score was used to predict postoperative pulmonary complications. ${ }^{22}$

ARISCAT, Assess Respiratory Risk in Surgical Patients in Catalonia; $\mathrm{FiO}_{2}$, inspiratory oxygen fraction; $\mathrm{Hb}$, haemoglobin; MAP, mean arterial pressure; $\mathrm{PaCO}_{2}$, carbon dioxide partial pressure; $\mathrm{PACU}$, postanaesthesia care unit; $\mathrm{PaO}_{2}$, arterial oxygen partial pressure; PEEP, positive end-expiratory pressure; $\mathrm{pH}$, acid-base status; $\mathrm{SpO}_{2}$, pulse oximetry haemoglobin saturation; VAS, visual analogue scale.

perhaps $5 \mathrm{~min}$ is insufficient time to achieve a steady-state $\mathrm{FEO}_{2}$ in some patients. Some authors found that slightly longer times (5.5 (4.8) $\mathrm{min}$ in healthy patients ${ }^{27}$ or 7.1 (2.1) in COPD patients) were required in mechanically ventilated patients. ${ }^{28}$ Another potential cause for the false negatives might be the percentage of pulse oximeter measurements because an error bias of up to $2 \%$ and differences in precision of up to $3 \%$ compared with the reference standard (carbon monoxide-oximeter) have been described for these data. ${ }^{29}$ Although we did not find false positives when the area was used to diagnose postoperative atelectasis, three of the 30 patients with a positive Air-Test result did not present an atelectasis mass of $>2 \%$. In addition to the bias and variation in precision discussed above, this error could also potentially be caused by overestimation of the atelectasis-induced alveolar shunt (based on the $\mathrm{SpO}_{2}-\mathrm{FiO}_{2}$ diagram ${ }^{11}$ ) because of the presence of low ventilation-perfusion $(\mathrm{V} / \mathrm{Q})$ zones that can appear during mechanical ventilation.

Table 3 Diagnostic accuracy, sensitivity, specificity and area under the curve (AUC) for detecting atelectasis with the Air-Test, as assessed against a reference standard (CT scans)

\begin{tabular}{lllll}
\hline & AUC $(\mathbf{9 5 \%} \mathbf{C l})$ & Sensitivity $(\%)$ & Specificity $(\%)$ & $\begin{array}{l}\text { Diagnostic accuracy } \\
(\%)\end{array}$ \\
\hline Air-Test $(\mathrm{n}=59)$ & $0.90(0.82$ to 0.98$)$ & 82.6 & 87.8 & 91.5 \\
\hline
\end{tabular}


In agreement with previous studies, the Air-Test indicated a $36 \%$ prevalence of postoperative atelectasis; Akça et al found a similar prevalence using CT scans in 30 patients after colon surgery. ${ }^{30}$ Our findings also correlate with the prevalence of postoperative $\mathrm{SpO}_{2}$ of $\leq 96 \%$ found by Severgnini et al where 12 of the 27 patients in the control group and eight of the 28 patients in the study group (representing a prevalence of $36 \%$ in the total population) had an $\mathrm{SpO}_{2}$ of $\leq 96 \%$ while breathing room air (unpublished data), but no atelectasis was diagnosed by chest radiography. ${ }^{31}$ Recently, an observational study that continuously monitored $\mathrm{SpO}_{2}$ in 833 unselected postoperative patients for 48 hours demonstrated a $37 \%$ prevalence of hypoxaemia $\left(\mathrm{SpO}_{2}<90 \%\right) .{ }^{9}$ However, in general, the rate of atelectasis usually reported is much lower. ${ }^{24}{ }^{32}$ Two recent trials, which together included more than 1200 patients, reported an atelectasis prevalence of around $15 \%$ when diagnosed by chest radiography. ${ }^{33}{ }^{34}$ However, this low prevalence might be explained by the low sensitivity and specificity of chest radiographs, and when compared with the prevalence observed in our study using CT scans, suggests that atelectasis is usually underestimated.

\section{LIMITATIONS}

There are several limitations to our study that we would like to acknowledge and expand on here. First, the Air-Test can only be applied to patients with a preoperative $\mathrm{SpO}_{2}$ of $\geq 97 \%$ on room air because at lower percentages it is impossible to differentiate whether the postoperative $\mathrm{SpO}_{2}$ measured indicates the presence of postoperative atelectasis or of previous lung disease. However, a high percentage of patients scheduled for surgery have an $\mathrm{SpO}_{2}$ of $\geq 97 \%$. $^{24}$ Second, intraoperative respiratory complications that decrease low $\mathrm{V} / \mathrm{Q}$ zones and therefore decrease $\mathrm{SpO}_{2}$ (eg, lung oedema or pneumothorax) may overestimate the atelectasis-induced alveolar shunt when this measurement is based on $\mathrm{SpO}_{2}-\mathrm{FiO}_{2}$. However, these postoperative complications in the immediate postoperative period rarely appear. $^{34}$ Third, compensatory mechanisms that come into play in the presence of atelectasis, such as hypoxic pulmonary vasoconstriction, decrease this shunt and therefore may also increase $\mathrm{SpO}_{2}$ and thus, based on the $\mathrm{SpO}_{2}-\mathrm{FiO}_{2}$ chart, ${ }^{11}$ would underestimate atelectasis. These latter two limitations may decrease the sensitivity and specificity of the Air-Test. Fourth, temporal factors could have also affected our results because of potential time delays between testing the arterial blood gases and performing the Air-Test and CT scans. However, even if this represents a problem, the results would have been negatively affected because a time-dependent reduction in postoperative atelectasis occurs as patients improve their breathing capacity. Fifth, it is possible that the pulse oximeter may have underestimated postoperative atelectasis in the presence of dyshaemoglobinaemia or overestimated it in the presence of anaemia, a low perfusion state, motion artefacts or hypothermia. ${ }^{29}$ Some of these limitations are related to the pulse oximeter and to the Air-Test itself, because shifts on the oxy-haemoglobin dissociation curve can affect the principle used by Jones and Jones to describe the $\mathrm{SpO}_{2}-\mathrm{FiO}_{2}$ diagram. ${ }^{11}$ However, this limitation was well controlled, as shown in tables 1 and 2. Finally, for the purpose of this study, an atelectatic area of less than $2 \%$ in the CT scan was considered negligible; although this percentage is not clinically relevant, these atelectasis, which are not diagnosed with the Air-Test, could potentially trigger an inflammatory response $^{35}$ that would therefore affect the rationale behind using this test.

\section{Implications for practice}

First, this is a pilot study and an adequately powered large external validation study looking at a more heterogeneous surgical population (eg, including obese patients without previous normal lung function or patients with a preoperative $\mathrm{SpO}_{2}$ of $<97 \%$ ) is still needed. This study should aim to validate the Air-Test as a surrogate for the presence of postoperative atelectasis and could also analyse it at different time points, with different pulse oximeter technologies, and in patients who had not previously received supplemental oxygen delivery during the postoperative period, in order to check if there is any correlation between the $\mathrm{SpO}_{2}$ values during the Air-Test and the area of atelectasis measured by the index test CT scan.

Second, the Air-Test could be used as a standardised screening test that could be applied in order to evaluate postoperative oxygenation before allowing patients to leave the PACU; its use could therefore contribute to speeding up the flow of patients through the PACU without jeopardising the provision of high-quality care because it might be able to more accurately identify patients without postoperative lung derecruitment (negative Air-Test results) from those with an increased risk of postoperative hypoxaemia (positive Air-Test results) ${ }^{36}$ and thus, those who should, ideally, be more closely monitored during this period and would likely benefit from measures to revert atelectasis. Thus, this non-invasive and inexpensive discriminatory test may have the potential to positively impact healthcare costs. ${ }^{37}$ Despite the potential benefits of employing this test, as shown by several studies, ${ }^{38}$ its more mainstream use remains uncertain. ${ }^{39}$ However, a clinical trial that uses the Air-Test to individually indicate the application of postoperative continuous positive end-expiratory pressure is currently ongoing. ${ }^{40}$

\section{CONCLUSIONS}

We have demonstrated that the Air-Test can be used as an accurate, simple, inexpensive, non-invasive and readily available method for diagnosing postoperative atelectasis, although these results should be confirmed in further, adequately powered studies.

\section{Author affiliations}

${ }^{1}$ Anesthesiology and Critical Care, Hospital Clínico Universitario Valencia, Valencia, Spain

${ }^{2}$ Anesthesiology and Critical Care, Consorci Hospital General Universitari de Valencia, Valencia, Spain 
${ }^{3}$ Department of Anesthesiology, Hospital Privado de Comunidad, Mar de Plata, Argentina

${ }^{4}$ Uppsala Universitet, Uppsala, Sweden

${ }^{5}$ CIBER de Enfermedades Respiratorias, Instituto de Salud Carlos III, Madrid, Spain

${ }^{6}$ Anesthesiology and Critical Care, Hospital Universitari Germans Trias i Pujol,

Badalona, Spain

${ }^{7}$ Department of Radiology, Hospital Clinico Universitario Valencia, Valencia, Spain

${ }^{8}$ ITACA Institute (Group IBIME), Universidad Politécnica, Valencia, Spain

${ }^{9}$ INCLIVA Clinical Research Institute, Valencia, Spain

${ }^{10}$ Research Unit, Hospital Universitario Dr. Negrin, Las Palmas de Gran Canaria, Spain

Contributors CF and FJB had full access to all data and are responsible for the integrity and the accuracy of the data analysis. Study design: CF, CR, JR, GT, FSS and FJB. Acquisition and analysis of data: CF, CR, JR, RD, GT, MS, PV, AV, FS, AJ, JuC, JN, CP, NP, CR, JR, JV and FJB. Interpretation of data: CF, GT and JaC. Drafting of the manuscript: CF, JV and FJB. Critical revision of the manuscript for intellectual content: CF, GT, FSS, JaC, JV and FJB.

Funding This research received no specific grants from any funding agency in the public, commercial or not-for-profit sectors.

Competing interests All the authors have completed the ICMJE uniform disclosure form atwww.icmje.org/coi_disclosure.pdf and declare they received/have: no support from any organisation for the submitted work; no financial relationships.

Ethics approval The study was approved by the Local Ethics Committee for Clinical Research in accordance with the Declaration of Helsinki (Chairperson: Dr Antonio Peláez), and registered on 28 December 2015 at

Provenance and peer review Not commissioned; externally peer reviewed.

Data sharing statement Additional unpublished data are available by request to the lead author.

Open Access This is an Open Access article distributed in accordance with the Creative Commons Attribution Non Commercial (CC BY-NC 4.0) license, which permits others to distribute, remix, adapt, build upon this work non-commercially, and license their derivative works on different terms, provided the original work is properly cited and the use is non-commercial. See: http://creativecommons.org/ licenses/by-nc/4.0/

(c) Article author(s) (or their employer(s) unless otherwise stated in the text of the article) 2017. All rights reserved. No commercial use is permitted unless otherwise expressly granted.

\section{REFERENCES}

1. Weiser TG, Regenbogen SE, Thompson KD, et al. An estimation of the global volume of surgery: a modelling strategy based on available data. Lancet 2008;372:139-44.

2. Tusman G, Böhm SH, Warner DO, et al. Atelectasis and perioperative pulmonary complications in high-risk patients. Curr Opin Anaesthesiol 2012;25:1-10.

3. Eichenberger A, Proietti S, Wicky S, et al. Morbid obesity and postoperative pulmonary atelectasis: an underestimated problem. Anesth Analg 2002;95:1788-92.

4. Xue FS, Li BW, Zhang GS, et al. The influence of surgical sites on early postoperative hypoxemia in adults undergoing elective surgery. Anesth Analg 1999;88:203-19.

5. Strandberg A, Tokics L, Brismar B, et al. Atelectasis during anaesthesia and in the postoperative period. Acta Anaesthesio Scand 1986;30:154-8.

6. Steinberg JM, Schiller HJ, Halter JM, et al. Alveolar instability causes early ventilator-induced lung injury independent of neutrophils. Am J Respir Crit Care Med 2004;169:57-63.

7. Magnusson L, Zemgulis V, Wicky S, et al. Atelectasis is a Major cause of hypoxemia and shunt after cardiopulmonary bypass: an experimental study. Anesthesiology 1997;87:1153-63.

8. Hedenstierna G, Tokics L, Strandberg A, et al. Correlation of gas exchange impairment to development of atelectasis during anaesthesia and muscle paralysis. Acta Anaesthesiol Scand 1986;30:183-91.

9. Sun Z, Sessler DI, Dalton JE, et al. Postoperative hypoxemia is common and persistent: a prospective Blinded Observational Study. Anesth Analg 2015;121:709-15.

10. Canet J, Ricos M, Vidal F. Early postoperative arterial oxygen desaturation. determining factors and response to oxygen therapy. Anesth Analg 1989;69:207-12.
11. Jones JG, Jones SE. Discriminating between the effect of shunt and reduced VA/Q on arterial oxygen saturation is particularly useful in clinical practice. J Clin Monit Comput 2000;16:337-50.

12. Howe JP, Alpert JS, Rickman FD, et al. Return of arterial PO2 values to baseline after supplemental oxygen in patients with cardiac disease. Chest 1975;67:256-8.

13. Fildissis G, Katostaras T, Moles A, et al. Oxygenation equilibration time after alteration of inspired oxygen in critically ill patients. Heart Lung 2010;39:147-52.

14. Tusman G, Groisman I, Fiolo FE, et al. Noninvasive monitoring of lung recruitment maneuvers in morbidly obese patients: the role of pulse oximetry and volumetric capnography. Anesth Analg 2014;118:137-44.

15. Lin J, Lin LA, Sandkoh S. A General Overview of Adaptive Randomization Design for clinical trials. J Biom Biostat 2016;07:2.

16. Tokics L, Hedenstierna G, Strandberg A, et al. Lung collapse and gas exchange during general anesthesia: effects of spontaneous breathing, muscle paralysis, and positive end-expiratory pressure. Anesthesiology 1987;66:157-67.

17. Hedenstierna G. Airway closure, atelectasis and gas exchange during anaesthesia. Minerva Anestesiol 2002;68:332-6.

18. Coussa M, Proietti S, Schnyder P, et al. Prevention of Atelectasis formation during the induction of General Anesthesia in Morbidly Obese Patients. Anesth Analg 2004;98:1491-5.

19. Rusca M, Proietti S, Schnyder P, Frascarolo P, et al. Prevention of atelectasis formation during induction of general anesthesia. Anesth Analg 2003;97:1835-9.

20. Borges JB, Okamoto VN, Matos GF, et al. Reversibility of lung collapse and hypoxemia in early acute respiratory distress syndrome. Am J Respir Crit Care Med 2006;174:268-78.

21. R Development Core Team [computer program] $R$ : a language and environment for statistical computing. R Foundation for Statistical Computing, Vienna, Austria 2008.

22. Fawcett T. An introduction to ROC analysis. Pattern Recognit Lett 2006;27:861-74.

23. Turck N, Vutskits L, Sanchez-Pena P, et al. A multiparameter panel method for outcome prediction following aneurysmal subarachnoid hemorrhage. Intensive Care Med 2010;36:107-15.

24. Canet J, Gallart L, Gomar C, et al. Prediction of postoperative pulmonary complications in a population-based surgical cohort. Anesthesiology 2010:113:1338-50.

25. Rothen HU, Sporre B, Engberg G, et al. Airway closure, atelectasis and gas exchange during general anaesthesia. $\mathrm{Br} J$ Anaesth 1998;81:681-6.

26. Witting MD, Lueck $\mathrm{CH}$. The ability of pulse oximetry to screen for hypoxemia and hypercapnia in patients breathing room air. $J$ Emerg Med 2001;20:341-8.

27. Cakar N, Tu rul M, Demirarslan A, et al. Time required for partial pressure of arterial oxygen equilibration during mechanical ventilation after a step change in fractional inspired oxygen concentration. Intensive Care Med 2001;27:655-9.

28. Sasse SA, Jaffe MB, Chen PA, et al. Arterial oxygenation time after an $\mathrm{FIO} 2$ increase in mechanically ventilated patients. Am J Respir Crit Care Med 1995:152:148-52.

29. Jubran A. Pulse oximetry. Crit Care 2015;19:272

30. Akça O, Podolsky A, Eisenhuber E, et al. Comparable postoperative pulmonary atelectasis in patients given $30 \%$ or $80 \%$ oxygen during and 2 hours after Colon resection. Anesthesiology 1999;91:991-8.

31. Severgnini P, Selmo G, Lanza C, et al. Protective mechanical ventilation during general anesthesia for open abdominal surgery improves postoperative pulmonary function. Anesthesiology 2013;118:1307-21.

32. Mazo V, Sabaté S, Canet J, et al. Prospective external validation of a predictive score for postoperative pulmonary complications. Anesthesiology 2014;121:219-31.

33. Hemmes SN, Gama de Abreu M, Pelosi P, et al. High versus low positive end-expiratory pressure during general anaesthesia for open abdominal surgery (PROVHILO trial): a multicentre randomised controlled trial. Lancet 2014;384:495-503.

34. Futier E, Constantin JM, Paugam-Burtz C, et al. A trial of intraoperative low-tidal-volume ventilation in abdominal surgery. $\mathrm{N}$ Engl J Med 2013;369:428-37.

35. Retamal J, Bergamini BC, Carvalho AR, et al. Non-lobar atelectasis generates inflammation and structural alveolar injury in the surrounding healthy tissue during mechanical ventilation. Crit Care 2014; 18:505.

36. Whitaker DK, Booth $\mathrm{H}$, Clyburn $\mathrm{P}$, et al. Immediate post-anaesthesia recovery 2013. Association of Anaesthetists of Great Britain and Ireland. Anesthesia 2013;68:288-97.

37. Fleisher LA, Linde-Zwirble WT, Incidence L-ZWT. Incidence, outcome, and attributable resource use associated with pulmonary 
and cardiac complications after Major small and large bowel procedures. Perioper Med 2014;3:7.

38. Squadrone V, Coha M, Cerutti E, et al. Continuous positive airway pressure for treatment of postoperative hypoxemia: a randomized controlled trial. JAMA 2005;293:589-95.

39. Ireland CJ, Chapman TM, Mathew SF, et al. Continuous positive airway pressure (CPAP) during the postoperative period for prevention of postoperative morbidity and mortality following Major abdominal surgery (review). Cochrane Database Syst Rev 2014;8:CD008930.

40. Ferrando $\mathrm{C}$, Soro $\mathrm{M}$, Canet $\mathrm{J}$, et al. Rationale and study design for an individualized perioperative open lung ventilatory strategy (iPROVE): study protocol for a randomized controlled trial. Trials 2015;16:193. 